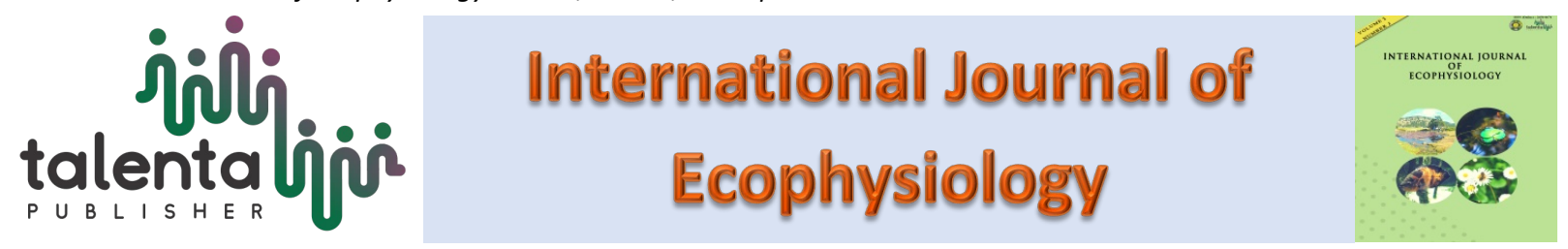

\title{
Physiological Response of Three Varieties of Cayenne Pepper (Capsicum frutescens) to Decreased Water Availability
}

\author{
Riyanto Sinaga, Dwi Intan Hardila, and Suci Rahayu \\ Department of Biology, Faculty of Mathematics and Natural Sciences, Universitas Sumatera Utara, \\ Medan, North Sumatra 20155, Indonesia
}

\begin{abstract}
Physiological response of three chili pepper varieties on water availability has been examined. The objective of this research was to determine the response of three chili pepper varieties on decreasing water availability. This research used completely randomized factorial design with two variables, namely: three varieties of chili pepper (Local, Genie, and Baskhara) and five different percentages of water availabilities (10, 25, 50,75 , and $100 \%$ ). that water availability had a significant effect on the decreasing of both shoot and root dry weight as well as on relative water content (RWC). Meanwhile, the decreasing water availability increased water use efficiency (WUE). The varieties of chili pepper showed a significant effect on shoot and root dry weight, shoot-root ratio, relative water content and on water use efficiency. The interaction of both variables showed a significant effect on water use efficiency as well as root dry weight.
\end{abstract}

Keyword: chili pepper, dry weight, varieties, water use efficiency, relative water content Received 8 June, 2020 | Revised 29 July, 2020 | Accepted 27 August, 2020

\section{Introduction}

Cayenne pepper (Capsicum frutescens) as a type of vegetable plays an important role in meeting national consumption needs and has the potential as an export commodity. Needs chili as the raw material varied growing cause of her use of chili as pharmaceuticals, cosmetics, pigments, mixing drinks and others, so that the raw material requirements of chili will continue to increase every year [1].

Chili production in Indonesia fluctuates greatly from year to year, while per capita consumption tends to continue to increase. Based on data from the Directorate General of Horticulture, Ministry of Agriculture (2008), the average yield of large chili and cayenne pepper in 2007 was

*Corresponding author at: Jl. Bioteknologi No. 1 Kampus Univ. Sumatera Utara, Padang Bulan, Medan, Indonesia 
6.30 tonnes/ha and 4.67 tonnes/ha, respectively. In 2007 the consumption of red chilies, green chilies, and cayenne pepper in Indonesia was $1.47 \mathrm{~kg} /$ capita/year respectively; 0.3 $\mathrm{kg} /$ capita/year; and $1.51 \mathrm{~kg} / \mathrm{capita} /$ year.

Cayenne pepper (Capsicum frustescens) is a horticultural plant that lives on soils with water conditions that are neither too high nor too low. Indonesia is located in the tropics with two seasons, rainy and dry. The prolonged drought causes the availability of groundwater to decrease. According to Kurnia [2], farmers generally rely on rain to irrigate their crops so that chili production is relatively low in certain months that do not get rain .

The water content in the plant varies greatly between 70 and $90 \%$, depending on temperature, species, and environment. Water is needed for many plant functions, such as solvents and chemical reaction media, transport medium for organic and inorganic substances, medium that provides turgor to plant cells, raw material for photosynthesis, and transpiration. Plants are said to experience water stress when the condition of plant cells loses water and is at a turgor pressure lower than its maximum value [3].

Plants that are exposed to drought during their growth will experience changes in morphology, physiology and biochemistry. Morphological changes in plants that experience drought include inhibition of root growth, plant height, stem diameter, leaf area and number of leaves. Physiological and biochemical effects are a decrease in yield or dry matter, changes in assimilate allocation, a decrease in the rate of photosynthesis, a decrease in the hydraulic diameter of root xylem and plant growth rate [4].

The demand and consumption of cayenne pepper, which remains high every year, demands the production of cayenne pepper that grows well on soils with not much water content. This is supported by the availability of dry land in Indonesia which is quite large compared to irrigated land, which has a great potential to produce cayenne pepper to meet consumer demand. Therefore it is necessary to conduct research to determine the effect of water availability on the physiological response of three varieties of cayenne pepper.

\section{Materials and Methods}

The materials used in this study were the seeds of three varieties of cayenne pepper (Genie, Bhaskara and Lokal varieties originating from Tanjung Morawa). Spraying of fungicides and insecticides on cayenne pepper is carried out every week to prevent pests and diseases.

The study used a factorial completely randomized design, namely three varieties of cayenne pepper and five levels of water availability $(10 \%, 25 \%, 50 \%, 75 \%, 100 \%)$ with three replications. The field capacity, permanent wilting point and available water content of the planting medium is calculated by the method of gravimetric. Variables measured are biomass 
(shoot dry weight and root dry weight), the ratio of root header, Relative Water Content (RWC) and Water Use Efficiency (WUE). Biomass was obtained by drying plants in the oven for 48 hours (until a constant weight was obtained). The canopy root ratio was obtained by comparing the shoot and root dry weight. Relative Water Content (RWC) is obtained by calculating the difference between wet weight and dry weight compared to the difference between turgor weight and plant dry weight. Ther Water Use Efficiency (WUE) was obtained from the result of plant dry weight divided by the water used during the study. Data were analyzed by ANOVA and followed by Duncan's Multiple Range Test at the 5\% level.

\section{Result and Discussion}

\section{Plant Dry Weight}

Decreased availability of water and cayenne pepper varieties shows the real effect restricted ap shoot dry weight, but their interaction both was not significant (Table 1). The canopy dry weight of the three varieties of cayenne pepper showed a decreasing response along with decreasing water availability. The decrease in canopy dry weight of the three varieties of cayenne pepper at $100 \%$ to $25 \%$ water availability was significantly different from the average crown dry weight at $10 \%$ water availability. The average canopy dry weight of local varieties $(28.61 \mathrm{~g})$ was greater and significantly different from Genie (3.72 g) and Bhaskara (1.89 g) varieties.

Table 1. Response shoot dry weight of three varieties of chili to the decline in the availability of water

\begin{tabular}{ccccccc}
\hline Variety & \multicolumn{4}{c}{ Water Availability (\%) (mean \pm SD) } & \multicolumn{3}{c}{ Average } \\
& $\mathbf{1 0 0}$ & $\mathbf{7 5}$ & $\mathbf{5 0}$ & $\mathbf{2 5}$ & $\mathbf{1 0}$ & \\
\hline Local (C1) & 36.6 & 30.03 & 29.77 & 25.2 & 21.47 & $28.61^{\mathbf{a}}$ \\
& $( \pm 4.33)$ & $( \pm 5.1)$ & $( \pm 4.79)$ & $( \pm 6.06)$ & $( \pm 6.96)$ & \\
Genie (C2) & 4.82 & 4.47 & 4,2 & 3.53 & 1.57 & $3.72^{\mathbf{b}}$ \\
& $( \pm 1.01)$ & $( \pm 1.57)$ & $( \pm 0.79)$ & $( \pm 0.25)$ & $( \pm 0.38)$ & \\
Bhaskara (C3) & 3,2 & 2.23 & 1.93 & 1.37 & 0.7 & $1.89^{\mathbf{b}}$ \\
& $( \pm 0.36)$ & $( \pm 0.15)$ & $( \pm 0.35)$ & $( \pm 0.57)$ & $( \pm 0.1)$ & \\
\hline
\end{tabular}

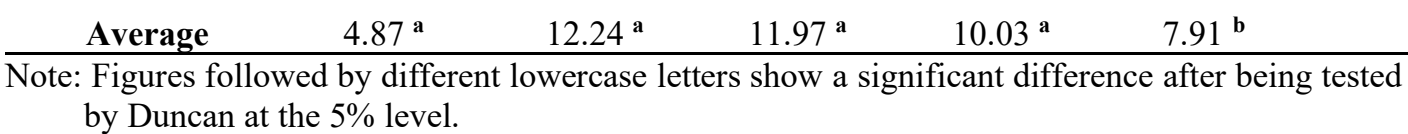

Plants experiencing water shortages tend to have lower biomass (dry weight) than control plants (field capacity). This is because the main component of green plants is $70-90 \%$ water which is a good medium for physiology and biochemistry of the plant itself. The same thing was also obtained by $\mathrm{Ai}[5]$ in a study of given water stress in ginger plant causes a decrease in ginger leaf biomass. Hanum et al. [6] stated that the effect of drought stress experienced by plants depends on the variety or type of plant, the size and duration of stress, and the growth period of the plant when given drought stress. 
In contrast to crown dry weight, decreased water availability, cayenne pepper varieties and the second interaction showed a significant effect on root dry weight (Table 2). The root dry weight of the three varieties of cayenne pepper showed the same response, namely the root dry weight decreased due to decreased water availability. This is in accordance with the opinion of Ai [5] that water stress experienced by plants can reduce the rate of plant growth in the vegetative phase, which includes the growth of roots, stems and leaves. Root dry weight of Genie and Bhaskara varieties at all levels of water availability was not significantly different, but significantly different from root dry weight of local varieties at all levels of water availability.

Local varieties always show the highest root dry weight since the condition is $100 \%$ to $10 \%$ water availability when compared to the other two varieties of cayenne pepper. The dry weight of the local variety roots at $10 \%, 25 \%$, and $50 \%$ water availability showed no significant difference, but was significantly different from the root dry weight at $75 \%$ and $100 \%$ water availability. This is because the availability of $10 \%-50 \%$ water causes plant roots to be unable to absorb water optimally so that the dry weight of the roots will decrease. The same thing was also explained by Sukarman et al.[7] stated that the physiological response of roots (root dry weight, number and effectiveness of roots) decreased rapidly with increasing drought stress. Drought stress $40 \%$ of field capacity reduces the growth and biomass of plants .

\section{Root Canal Ratio}

Cayenne pepper varieties showed a significant effect on the root canopy ratio value, but the level of water availability and their interaction had no significant effect (Table 3). The mean root canopy ratio of local varieties (1.78) was greater and not significantly different from Genie varieties (1.55), but significantly different from Bhaskara varieties (0.86). All levels of water availability showed no significant difference in the ratio of the three varieties of cayenne pepper.

Table 2. Response root dry weight of three varieties of chili to the decline in the availability of water

\begin{tabular}{ccccccc}
\hline Variety & \multicolumn{5}{c}{ Water Availability (\%) (mean \pm SD) } & \multirow{2}{*}{ Average } \\
\cline { 2 - 5 } & $\mathbf{1 0 0}$ & $\mathbf{7 5}$ & $\mathbf{5 0}$ & $\mathbf{2 5}$ & $\mathbf{1 0}$ & \\
\hline Local (C1) & $21.77^{\mathbf{a}}$ & $20.03^{\mathbf{a}}$ & $18.67^{\mathbf{b}}$ & $12.27^{\mathbf{b}}$ & $11.93^{\mathbf{b}}$ & \multirow{2}{*}{$16.93^{\mathbf{a}}$} \\
& $( \pm 6.43)$ & $( \pm 4.25)$ & $( \pm 4.25)$ & $( \pm 1,2)$ & $( \pm 2.14)$ & \\
Genie (C2) & $4.37^{\mathbf{c}}$ & $3.03^{\mathbf{c}}$ & $2.57^{\mathbf{c}}$ & $2.07^{\mathbf{c}}$ & $0.9^{\mathbf{c}}$ & $2.59^{\mathbf{b}}$ \\
& $( \pm 1.16)$ & $( \pm 0.21)$ & $( \pm 0.46)$ & $( \pm 0.45)$ & $( \pm 0.3)$ & \\
Bhaskara (C3) & $3.67^{\mathbf{c}}$ & $2.33^{\mathbf{c}}$ & $2.03^{\mathbf{c}}$ & $1.87^{\mathbf{c}}$ & $1,2^{\mathbf{c}}$ & \multirow{2}{*}{$2.22^{\mathbf{b}}$} \\
& $( \pm 0.84)$ & $( \pm 0.93)$ & $( \pm 0.61)$ & $( \pm 0.42)$ & $( \pm 0.5)$ & \\
\hline \multirow{2}{*}{ Average } & $9.94^{\mathbf{a}}$ & $8.46^{\mathbf{a}}$ & $7.76^{\mathbf{a}}$ & $5.4^{\mathbf{b}}$ & $4.68^{\mathbf{b}}$ & \\
\hline
\end{tabular}

Note: Figures followed by different lowercase letters show a significant difference after being tested by Duncan at the 5\% level. 
The canopy ratios of local and genie varieties showed greater crown dry weight than root dry weight. The canopy ratio of Bhaskara variety showed that the root dry weight was greater than the crown dry weight. Solichatun et al. [8] explained that this occurs as a result of plants experiencing drought stress that will allocate most of their photosynthesized results to storage organs.

Table 3. Response headers ratio a kar three varieties of chili terh adap decreased availability of water.

\begin{tabular}{ccccccc}
\hline Variety & \multicolumn{5}{c}{ Water Availability (\%) (mean \pm SD) } & \multirow{2}{*}{ Average } \\
\cline { 2 - 5 } & $\mathbf{1 0 0}$ & $\mathbf{7 5}$ & $\mathbf{5 0}$ & $\mathbf{2 5}$ & $\mathbf{1 0}$ & \\
\hline Local (C1) & 1.79 & 1.59 & 1.69 & 2.05 & 1.77 & $1.78^{\mathbf{a}}$ \\
& $( \pm 0.63)$ & $( \pm 0.6)$ & $( \pm 0.64)$ & $( \pm 0.45)$ & $( \pm 0.3)$ & \\
Genie (C2) & 1.03 & 1.49 & 1.66 & 1.77 & 1.8 & $1.55^{\mathbf{a}}$ \\
& $( \pm 0.14)$ & $( \pm 0.6)$ & $( \pm 0.37)$ & $( \pm 0.44)$ & $( \pm 0.33)$ & \\
Bhaskara & 0.91 & 1.04 & 0.99 & 0.72 & 0.64 & $0.86^{\mathbf{b}}$ \\
(C3) & $( \pm 0.22)$ & $( \pm 0.29)$ & $( \pm 0.25)$ & $( \pm 0.17)$ & $( \pm 0.2)$ & \\
\hline Average & $1.24^{\mathbf{a}}$ & $1.37^{\mathbf{a}}$ & $1.45^{\mathbf{a}}$ & $1.51^{\mathbf{a}}$ & $1.40^{\mathbf{a}}$ & \\
\hline
\end{tabular}

Note: Figures followed by different lowercase letters show a significant difference after being tested by Duncan at the $5 \%$ level.

\section{Relative Water Content (RWC)}

The decrease in water availability and cayenne pepper varieties showed a significant effect on RWC, but the interaction between the two had no significant effect (Table 4). The RWC of the three varieties of cayenne pepper showed the same response, namely the RWC decreased along with the decrease in water availability. The average reduction in RWC of the three varieties of ra wit chili at $100 \%, 75 \%$ and $50 \%$ water availability shows no significant difference, but is significantly different from the RWC average of $25 \%$ and $10 \%$ water availability. The average RWC of Bhaskara variety (43.80\%) was greater and not significantly different from Genie variety (41.86\%), but significantly different from local varieties (35.09\%).

Table 4. Response Relative Water Content (RWC) three varieties of chili to the decline in the availability of water

\begin{tabular}{ccccccc}
\hline Variety & \multicolumn{7}{c}{ Water Availability (\%) $(\mathbf{~ M e a n ~} \pm$ SD) } & Average \\
& $\mathbf{1 0 0}$ & $\mathbf{7 5}$ & $\mathbf{5 0}$ & $\mathbf{2 5}$ & $\mathbf{1 0}$ & \\
\hline Local (C1) & 39.79 & 35.91 & 35.05 & 34.52 & 30.16 & $35.09^{\mathbf{a}}$ \\
& $( \pm 2.45)$ & $( \pm 6.54)$ & $( \pm 2,2)$ & $( \pm 2.86)$ & $( \pm 4.41)$ & \\
Genie (C2) & 49.41 & 43.73 & 40.31 & 38.45 & 37.42 & $41.86^{\mathbf{b}}$ \\
& $( \pm 5.67)$ & $( \pm 1.65)$ & $( \pm 6.49)$ & $( \pm 3)$ & $( \pm 0.32)$ & \\
Bhaskara (C3) & 48.33 & 43.73 & 42.82 & 42.53 & 41.60 & $43.80^{\mathbf{b}}$ \\
& $( \pm 2.43)$ & $( \pm 2,2)$ & $( \pm 0.84)$ & $( \pm 1.83)$ & $( \pm 5.92)$ & \\
\hline Average & $45.84^{\mathbf{a}}$ & $41.12^{\mathbf{a}}$ & $39.39^{\mathbf{a}}$ & $38.50^{\mathbf{b}}$ & $36.39^{\mathbf{b}}$ & \\
\hline
\end{tabular}

Note: Figures followed by different lowercase letters show a significant difference after being tested by Duncan at the $5 \%$ level.

Leaf are experiencing a shortage of water tend to have a lighter mass when compared with leaves that are not experiencing a shortage of water, which is why the value of RWC 
leaves of three varieties of chili decreases with decreasing availability of water. Dahlan et al. [9] and Mathius [10] explained in their research that water content and varieties had a significant effect on leaf water potential, leaf water content and relative water content (RWC) where the RWC value would decrease when given a longer drought stress

\section{Water Use Efficiency (EPA)}

Decreased availability of water, cayenne pepper varieties, and their interaction showed a significant effect on the WUE (Table 5). All three varieties of chili showed a different WUE response, the Genie varieties and Local varieties increase with the decrease of availability of water, but the highest decrease found when the level of water availability $10 \%$. The WEA fluctuating in the Bhaskara varieties with decreasing water availability.

Table 5. Response Efficient Use of Water (EPA) three varieties of chili to the decline in the availability of water.

\begin{tabular}{ccccccc}
\hline Variety & \multicolumn{5}{c}{ Water Availability (\%) (Mean \pm SD) } & \multirow{2}{*}{ Average } \\
\cline { 2 - 5 } & $\mathbf{1 0 0}$ & $\mathbf{7 5}$ & $\mathbf{5 0}$ & $\mathbf{2 5}$ & $\mathbf{1 0}$ & \\
\hline Local (C1) & $65.75^{\mathbf{b}}$ & $63.11^{\mathbf{b}}$ & $74.52^{\mathbf{a}}$ & $92.95^{\mathbf{a}}$ & $105.66^{\mathbf{a}}$ & $80.4^{\mathbf{a}}$ \\
& $( \pm 8.22)$ & $( \pm 1.09)$ & $( \pm 3.71)$ & $( \pm 16.49)$ & $( \pm 28.52)$ & \\
Genie (C2) & $26.8^{\mathbf{c}}$ & $26.91^{\mathbf{c}}$ & $30.98^{\mathbf{c}}$ & $41.86^{\mathbf{c}}$ & $20.9^{\mathbf{d}}$ & $29.49^{\mathbf{b}}$ \\
& $\left( \pm 5.05^{\mathbf{b}}\right)$ & $( \pm 2.8)$ & $( \pm 1.61)$ & $( \pm 3.26)$ & $( \pm 5.64)$ & \\
Bhaskara (C3) & $31.44^{\mathbf{c}}$ & $24.94^{\mathbf{c}}$ & $27.51^{\mathbf{c}}$ & $37.69^{\mathbf{c}}$ & $24.05^{\mathbf{c}}$ & $29.13^{\mathbf{b}}$ \\
& $( \pm 4.61)$ & $( \pm 5.89)$ & $( \pm 6.21)$ & $( \pm 11.08)$ & $( \pm 7,6)$ & \\
\hline Average & $41.33^{\mathbf{a}}$ & $38.32^{\mathbf{b}}$ & $44.34^{\mathbf{a}}$ & $57.5^{\mathbf{a}}$ & $50.2^{\mathbf{a}}$ & \\
\hline
\end{tabular}

Note: Figures followed by different lowercase letters show a significant difference after being tested by Duncan at the $5 \%$ level.

Water Use Efficiency of Bhaskara variety at all levels of water availability was not significantly different from Genie varieties at levels of water availability of $100 \%, 75 \%, 50 \%$, and $25 \%$, but different from $10 \%$ and Local Genie at all levels of water availability. Water Use Efficiency of Genie varieties at the level of water availability of $10 \%$ was significantly different from all interactions of treatment of Local, Genie, and Bhaskara varieties at all levels of water availability.

Efficiency of Water Use for Local Varieties shows a higher EPA since the condition of $100 \%$ to $10 \%$ of water availability compared to other varieties. Water Use Efficiency at the level of $100 \%$ and $75 \%$ shows an insignificant difference, but is significantly different from EPA at the water availability levels of $50 \%, 25 \%$, and $10 \%$. The same thing was obtained by Bahru et al. [11] where irrigation techniques for part of the root area can improve Water Use Efficiency (EPA) in soybean plants. Water Use Efficiency is related to the amount of water used to produce crops (biomass). Water Use Efficiency increases at the level of $60 \%$ water availability and decreases at the level of $80 \%$ and $100 \%$ water availability [12]. 


\section{Conclusion}

Based on the results of research and discussion, it is concluded that the varieties of chili pepper showed a significant effect on shoot and root dry weight, shoot-root ratio, relative water content and on water use efficiency. The interaction of both variables showed a significant effect on water use efficiency as well as root dry weight.

\section{REFERENCES}

[1] Zulkifli, AK, Yusuf, A., Amrizal, Iskandar, T., Adil, M., Ali, NM, Sulaeman, B., Roswita, Azis, A., Fahrizal, TM, Umar, Z., Djuanda, T. Assembly of Red Chili Cultivation Technology. National Research Institute for Red Chili SUT K ajian, Banda Aceh. 2000.

[2] Kurnia, U. The prospect of dry season crop irrigation. Journal of Agricultural Research and Development. 23 (4): 130 -138. 2004.

[3] Hanum, C. Plant Ecology. USU Press, Medan. p. 114-115,117. 2009.

[4] Sinaga, R. The analysis model of resistance $r$ um put the elephant and king grass as a result of drought stress response by root anatomy and d aun. Journal of Biology Sumatra. 2 (1): 17-20. 2007.

[5] Ai, NS. Biomass and total chlorophyll content of jahe leaves (Zingiber officinale L.) which are experiencing drought stress. Scientific Journal of Science . 11 (1): 1-4. 2011

[6] Hanum, C., Mugnisjah, WQ, Yahya, S., Sopandy, D., Idris, K., Sahar , A. Soybean root growth in aluminum stress, drought and aluminum double stress and drought. Agritrop . 26 (1): 13-18. 2007.

[7] Sinaga, R. The analysis model of resistance $r$ um put the elephant and king grass as a result of drought stress response by root anatomy and d aun. Journal of Biology Sumatra. 2 (1): 17-20. 2007.

[8] Solichatun, Anggarwulan, E., Mudyantini, W . The effect of water availability on growth and active ingredient content of saponins of ginseng $\mathrm{j}$ awa (Talinum paniculatum Gaertn.). Biopharmaceutical. 3 (2): 47-51. 2005.

[9] Dahlan, M., Rahardjo , S., Kusmarwiyah, R., Arifin , Z., Nikmatullah , A. Growth and yield of three soybean varieties in different soil moisture conditions. Agroteksos. 22 (1): 27-37. 2012.

[10] Mathius, NT, Wijana , G., Guharja, E., Aswidinnoor , H., Yahya, S., Subronto. The response of the sawit coconut plant (Elaeis guineensis Jacq.) To drought stress . Plantation Tower. (2): 28-44. 2001.

[11] Bahru, A., Hasid, R., Muhiddin, Erawan, D. The effect of half-root area irrigation on water use efficiency and soybean (Glycine max) production in the dry season. Indonesian Journal of Agronomy. 40 (1): 36-41. 2012.

[12] Haryati, U., Sinukaban , N., Murtilaksono, K., Abdurachman , A . Management a llow Able deplation (MAD) level for water use efficiency of pepper plants on land kanhapludults t amanbogo, Lampung. Journal of Soil and Climate. (31): 11-25. 2010. 
[13] Sukarman, Darwati, I., Rusmin, D . Morphological and physiological characters of $t$ ara (Vinca rosea L.) in several water stresses. Littri's Journal. 6 (2): 50-54. 2000. 